\title{
RNA profiling reveals familial aggregation of molecular subtypes in non-BRCA1/2 breast cancer families
}

\author{
Martin J Larsen 1,2*, Mads Thomassen 1,2, Qihua Tan 1,3, Anne-Vibeke Lænkholm4, Martin Bak ${ }^{5}$, Kristina P Sørensen ${ }^{1,2}$,
} Mette Klarskov Andersen ${ }^{6}$, Torben A Kruse ${ }^{1,2}$ and Anne-Marie Gerdes ${ }^{6}$

\begin{abstract}
Background: In more than $70 \%$ of families with a strong history of breast and ovarian cancers, pathogenic mutation in BRCA1 or BRCA2 cannot be identified, even though hereditary factors are expected to be involved. It has been proposed that tumors with similar molecular phenotypes also share similar underlying pathophysiological mechanisms. In the current study, the aim was to investigate if global RNA profiling can be used to identify functional subgroups within breast tumors from families tested negative for BRCA1/2 germline mutations and how these subgroupings relate to different breast cancer patients within the same family.

Methods: In the current study we analyzed a collection of 70 frozen breast tumor biopsies from a total of 58 families by global RNA profiling and promoter methylation analysis.

Results: We show that distinct functional subgroupings, similar to the intrinsic molecular breast cancer subtypes, exist among non-BRCA1/2 breast cancers. The distribution of subtypes was markedly different from the distribution found among BRCA1/2 mutation carriers. From 11 breast cancer families, breast tumor biopsies from more than one affected family member were included in the study. Notably, in 8 of these families we found that patients from the same family shared the same tumor subtype, showing a tendency of familial aggregation of tumor subtypes ( $p$-value $=1.7 e-3)$. Using our previously developed BRCA1/2-signatures, we identified 7 non-BRCA1/2 tumors with a $B R C A 1$-like molecular phenotype and provide evidence for epigenetic inactivation of BRCA1 in three of the tumors. In addition, 7 BRCA2-like tumors were found.

Conclusions: Our finding indicates involvement of hereditary factors in non-BRCA1/2 breast cancer families in which family members may carry genetic susceptibility not just to breast cancer but to a particular subtype of breast cancer. This is the first study to provide a biological link between breast cancers from family members of high-risk non-BRCA1/2 families in a systematic manner, suggesting that future genetic analysis may benefit from subgrouping families into molecularly homogeneous subtypes in order to search for new high penetrance susceptibility genes.
\end{abstract}

Keywords: Hereditary breast and ovarian cancer syndrome, RNA profiling, non-BRCA1/2, Gene expression analysis, Microarray analysis, Molecular subtypes, Promoter methylation

\footnotetext{
* Correspondence: martin.larsen@rsyd.dk

'Department of Clinical Genetics, Odense University Hospital, Sdr. Boulevard 29, Odense 5000, Denmark

${ }^{2}$ Human Genetics, Clinical Institute, University of Southern Denmark, Odense, Denmark

Full list of author information is available at the end of the article
}

\section{Biomed Central}

(c) 2014 Larsen et al.; licensee BioMed Central Ltd. This is an Open Access article distributed under the terms of the Creative Commons Attribution License (http://creativecommons.org/licenses/by/2.0), which permits unrestricted use, distribution, and reproduction in any medium, provided the original work is properly cited. The Creative Commons Public Domain Dedication waiver (http://creativecommons.org/publicdomain/zero/1.0/) applies to the data made available in this article, unless otherwise stated. 


\section{Background}

Breast cancer is the most common malignant disease and the leading cause of cancer death among women [1]. It is estimated that approximately $5-10 \%$ of all breast cancers have a strong hereditary component. High-risk families often show an apparently dominant inheritance pattern of breast cancer cases and are often characterized by early age of onset and presence of ovarian cancers, bilateral breast cancers, and male breast cancers. Germline mutations in BRCA1 and BRCA2 only explain the breast cancer risk in approximately one fourth of these families, however, it is expected that additional $B R C A 1 / 2$ mutations still remain undetected by the screening methods used today $[2,3]$.

Despite intensive research, genetic linkage analysis, genome-wide association studies (GWAS) and most recently next generation sequencing (NGS) exome studies have failed to identify other common high penetrance breast cancer susceptibility genes, like BRCA1 and $B R C A 2$, and it is now generally accepted that no single high penetrance gene is likely to account for a larger fraction of the remaining familial aggregation [4-9]. Instead, the remaining genetic susceptibility is expected to be explained by a mixture of rare high-risk variants and polygenic mechanisms involving more common and/or rare low-penetrance alleles or rare moderate penetrance genes, acting in concert to confer a high breast cancer risk $[3,10,11]$. Furthermore, a fraction of the familial aggregation of breast cancer cases may be explained by sharing of common environmental risk factors and exogenous hormone use, or be just random aggregation of sporadic breast cancers.

Several rare inactivating mutations in other high penetrance genes have been described to contribute to an increased breast cancer risk, such as TP53, CDH1, PTEN, $S T K 11, R A D 51 C$, and $R A D 51 D$ and in the low/moderate penetrance genes ATM, CHEK2, BRIP1, and PALB2 among others (reviewed by Vargas et al. [12]). Most are involved in the maintenance of genomic integrity and DNA repair mechanisms and many are associated with multiple cancer syndromes. However, these only explain a minor fraction of the remaining breast cancer risk, leaving the etiology of the remaining high-risk families unexplained. This results in less optimal genetic counseling and risk reducing options for healthy members in these families. It is therefore highly important to identify the cancer predisposition defects of the unsolved highrisk non-BRCA1/2 families.

The histopathologic characteristics of $B R C A 1$ and $B R C A 2$ breast tumors are well described. BRCA1 tumors are frequently grade 3 , estrogen receptor (ER) negative, progesterone receptor (PR) negative and HER2-negative (triple-negative), while the majority of BRCA2 tumors are grade 2/3, ER-positive and HER2-negative [13].
Contrary, familial non-BRCA1/2 breast cancers have been shown to be a very heterogeneous group with varied histopathologic features [14,15].

Gene expression profiling studies of sporadic/unselected breast cancers have revealed the existence of at least five clinically relevant subgroups: basal-like, HER2-enriched, luminal A (lumA) and luminal B (lumB) [16-21]. The molecular subtypes correspond broadly to known histopathological characteristics and are associated with different clinical outcomes. Basal-like cancers are mostly highgrade, triple-negative tumors with high expression of basal epithelial markers such as $C K 5 / 14 / 17$; while HER2enriched cancers are associated with amplification of the HER2-gene. LumA cancers are typically low-proliferative, $\mathrm{ER}+$ tumors while lumB are high-proliferative, ER + cancers. Luminal cancers show high expression of luminalassociated genes such as $C K 8 / 18$. In addition to these four subtypes, a normal-like subtype has also been identified which exhibit high similarity with normal breast epithelium.

Only few gene expression profiling studies of hereditary breast cancers have been published. Recently, we and others have shown that BRCA1 mostly are basal-like while the majority of $B R C A 2$ tumors are of luminal subtypes [22-24]. Non-BRCA1/2 cancers have been reported to be distributed across the different molecular subtypes similar to the sporadic cancers; though several studies indicate an enrichment of the lumA subtypes among non-BRCA1/2 tumors compared to sporadic/unselected cases $[22,23,25]$.

Because of the underlying genetic heterogeneity of the non-BRCA1/2 families, the search for more highsusceptibility genes is particular complicated. Even though promising technologies such as exome sequencing provides new opportunities, such attempts have so far failed to identify new high-susceptibility genes [7-9]. The recent negative results using exome sequencing indicate that intelligent stratification is needed in order to reduce heterogeneity. One possible approach to reduce heterogeneity could be to pre-select cases based on molecular tumor characteristics.

In the present study, we have used genome-wide RNA profiling analysis for molecular characterization of familial non-BRCA1/2 tumors. It has been proposed that tumors with similar molecular characteristics are a result of similar pathophysiological mechanisms. Thus, stratifying patients by molecular tumor subgroups based on RNA profiles could potentially facilitate the identification of new breast cancer susceptibility genes by increasing the statistical power of linkage analysis, genome-wide association, or exome sequencing studies. Here, we studied how RNA profiling can be used to identify functional subgroups within tumors from familial non-BRCA1/2 breast cancers and to what extent these subgroupings relate to 
different patients in the same family. Furthermore, previously developed gene signatures were applied to identify tumors with BRCA1-like and BRCA2-like phenotypes within the group of non-BRCA1/2 tumors.

\section{Methods}

\section{Ethics statement}

The study was carried out as a retrospective register study and in accordance with the Helsinki Declaration. The study has been approved by The National Committee on Health Research Ethics of Denmark (S-VF-20020142), waiving the requirement for informed consent for the study.

\section{Patient material}

The study was performed on frozen primary breast tumor samples collected from 1982 to 2008. Samples were obtained from the tumor biobanks of Dept. of Pathology, Odense University Hospital and Danish Breast Cancer Cooperative Group (DBCG). Breast tumor tissue from 125 patients with germline mutations in $\operatorname{BRCA1}(n=33)$ or $B R C A 2(n=22)$ or with no detectable germline mutation in BRCA1 or BRCA2 $(n=70)$ were included in the study. During the period from 2000 to 2005 (64\% of the included patients) genetic mutation screening were conducted using a setup consisting of denaturing highperformance liquid chromatography (DHPLC), protein truncation test (PTT) and Sanger sequencing analysis in addition to Multiplex Ligation-dependent Probe Amplification (MLPA) for detection of larger copy number abnormalities. From 2006 (36\% of the included patients), the DHPLC method were replaced by Temperature Gradient Capillary Electrophoresis (TGCE) for prescreening of small exons. The patients were all part of a family referred to genetic counseling (Dept. of Clinical Genetics, Odense University Hospital or Dept. of Clinical Genetics, Rigshospitalet) because of a family history of breast cancer. The families were recruited in the period from 2003 to 2009. Inclusion criteria were 1) a pedigree indicating autosomal dominant inheritance of a breast cancer predisposition or 2) presence of ovarian cancer in a pedigree with breast cancer cases or 3 ) a very young age at diagnosis of breast cancer (before 35 years). A three generation pedigree was constructed on all families depending on the information available from the families. All cancer diagnoses were confirmed by hospital records, histopathology reports or death certificates. Serving as a representative control group, primary breast tumor samples $(n=128)$ were randomly selected among available samples originating from the same department and time period as for the hereditary samples. The family histories of the control patients were unknown, but none of the patients had been referred to genetic counseling at Odense University Hospital, from where the vast majority of patients were recruited, and are therefore here referred to as sporadic. We have previously described gene expression analyses of a subset of the included tumors (BRCA1, BRCA2 and sporadic cases) [24]. Tumor and patient characteristics are summarized in Table 1. Characteristics of the included families are summarized in Table 2.

\section{Histopathological review}

Samples included in the study contained at least 50\% tumor cells determined by representative hematoxylineosin stainings. Tumor samples were macro-dissected to increase purity and remove normal cell-enriched areas. Histopathological data and ER, PR, and HER2 status determined by immunohistochemistry (IHC) were obtained from DBCG. In addition, gene-expression data were used to determine ER, PR, and HER2 status as previously described [24].

\section{Gene expression analysis}

Gene expression analysis was performed using a customized version of Agilent SurePrint G3 Human GE $8 \times 60 \mathrm{~K}$ Microarray and raw data were pre-processed as previously described [24]. Microarray data have been deposited to the Gene Expression Omnibus (GSE49481).

\section{Detection of promoter methylation}

Hypermethylation of the $B R C A 1$ and $B R C A 2$ promoter regions were determined by the methylation-specific MLPA kit ME001C (MRC-Holland) using DNA extracted from freshly frozen tumor tissue. Blood DNA from 6 healthy donors were used as reference. CpGenome Universal Methylated DNA (Millipore) was used as positive control. A methylation ratio $>0.2$ was considered as positive promoter methylation. Methylation status was successfully determined in 235 out of the 253 samples analyzed by gene expression analysis.

\section{Data analysis \\ Unsupervised methods}

Unsupervised hierarchical clustering (Euclidian metric, complete linkage) and principal-component analysis (PCA) were carried out in Qlucore Omics Explorer. Expression levels of each gene had been standardized to zero mean and unit variance.

\section{Molecular subtype classification}

PAM50 subtype classifier described by Parker et al. was used to classify tumors into five intrinsic molecular subtypes using the R package genefu [20]. Probes for all 50 PAM50 genes were present on the Agilent microarray used. 
Table 1 Patient and tumor characteristics

non-BRCA1/2 $(n=70) \quad$ BRCA1 $(n=33) \quad$ BRCA2 $(n=22) \quad$ Sporadic $(n=128)$

Estrogen receptor

$\begin{array}{lcccc}\text { ER+ } & 8.6 \% & 42.4 \% & 90.9 \% & 83.6 \% \\ \text { ER- } & 21.4 \% & 57.6 \% & 9.1 \% & 16.4 \%\end{array}$

Progesterone receptor

$\begin{array}{lllll}\text { PR+ } & 65.7 \% & 21.2 \% & 72.7 \% & 61.7 \% \\ \text { PR- } & 34.3 \% & 78.8 \% & 27.3 \% & 38.3 \%\end{array}$

HER2 status

HER2+

$14.3 \%$

$9.1 \%$

$4.5 \%$

$16.4 \%$

HER2-

$85.7 \%$

$90.1 \%$

$95.5 \%$

$83.6 \%$

Lymph node

$\mathrm{LN+}$

$41.4 \%$

$52.9 \%$

$5.7 \%$

Tumor size

NA

Mean tumor size, $\mathrm{mm}$ [ $\pm \mathrm{SD}]$

$25[ \pm 18]$

$45.5 \%$

$63.6 \%$

$39.8 \%$

$48.5 \%$

$31.8 \%$

$58.6 \%$

$6.1 \%$

$4.5 \%$

$1.6 \%$

$23[ \pm 10]$

$25[ \pm 13]$

$25[ \pm 16]$

Histologic grade

Grade 1
Grade 2
Grade 3
NA
Invasive ductal carcinoma
Invasive lobular carcinoma
Mucinous carcinoma
Medullary carcinoma
Tubular carcinoma
Metaplastic carcinoma
Other
NA

$17.1 \%$

$40 \%$

$28.6 \%$

$14.3 \%$

$9.1 \%$

$21.2 \%$

$54.5 \%$

$15.2 \%$

$78.6 \%$

$12.9 \%$

$84.8 \%$

$3.0 \%$

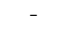

$1.4 \%$

$6.1 \%$

$1.4 \%$

$-$

$5.7 \%$

$6.1 \%$

$50[29-86]$
$47.1 \%$
$52.9 \%$

Median age, years [range]

$<50$ years

$\geq 50$ years

$52.9 \%$

Premenopausal

Perimenopausal

Postmenopausal

Other

NA

\section{$2.9 \%$}

$38.6 \%$

$2.9 \%$

$2.9 \%$

$\begin{array}{cc}9.1 \% & 25.0 \% \\ 50.0 \% & 37.5 \% \\ 31.8 \% & 22.7 \% \\ 9.1 \% & 14.8 \%\end{array}$

$86.4 \%$

$82.0 \%$

$9.4 \%$

$1.6 \%$

$0.8 \%$

$2.3 \%$

$16 \%$

$2.3 \%$

$4.5 \%$

$43.5[28-72]$
$68.2 \%$
$31.8 \%$

61 [27-95]

$16.4 \%$

$83.6 \%$

$31.8 \%$
$23.4 \%$

$60.6 \%$

$68.2 \%$

$11.7 \%$

$36.4 \%$

$4.5 \%$

$60.9 \%$

$1.6 \%$

$3.0 \%$

$2.3 \%$

\section{Familial aggregation testing}

Aggregation of breast cancer subtypes in the observed families was tested using computer simulation. In the simulation, the observed tumor samples were randomly assigned to each family with the number of assigned tumors as observed in the family. The counts for tumor subtypes falling into each family were recorded. The procedure was repeated for 100,000 times based on which the empirical $p$-value for testing familial aggregation of a tumor subtype was calculated as the proportion 
Table 2 Summarized characteristics of the non-BRCA1/2 families $(\mathbf{n}=\mathbf{5 8})$

\begin{tabular}{ll}
\hline & Percentage \\
\hline Breast c. + ovarian c. & $36 \%$ \\
2 Breast c. & $33 \%$ \\
3 Breast c. & $24 \%$ \\
$>3$ Breast c. & $26 \%$ \\
Bilateral breast c. & $29 \%$ \\
Early onset breast c. (<35 years) & $10 \%$ \\
Male breast c. & $2 \%$ \\
Prostate c. & $17 \%$ \\
Colon c. & $19 \%$ \\
Cervical c. & $14 \%$ \\
Rectal c. & $14 \%$ \\
Malignant melanoma & $12 \%$ \\
Ventricular c. & $12 \%$ \\
Other cancers & $52 \%$ \\
\hline
\end{tabular}

of replicates with eight or more families having two or more tumors of the same subtype.

A microarray gene expression dataset published by Hedenfalk et al. was used for confirmative assessment of familial aggregation of molecular breast cancer subtypes [26]. Pre-processing steps of the dataset are described in the supplementary information (see Additional file 1: Methods S1).

\section{Prediction of BRCA1 and BRCA2 associated breast cancers}

Two subtype specific gene signatures have previously been developed by our group using the included BRCA1, $B R C A 2$ and sporadic samples [24]. Using the 110-gene basal BRCA1 signature, we were able to distinguish $B R C A 1$ from sporadic tumors among basal-like samples and the 100-gene lumB $B R C A 2$ signature enabled us to separate $B R C A 2$ tumors from sporadic among lumB samples, both with high accuracies. Here, we used the gene signatures, employing the support vector machines algorithm (linear kernel), to identify tumors with BRCA1-like and $B R C A 2$-like phenotype within basal-like and lumB non-BRCA1/2 tumors, respectively.

\section{Results}

\section{Pathological characteristics of patient material}

In the present study, frozen primary breast tumor samples were collected from 70 non-BRCA1/2, 33 BRCA1, $22 B R C A 2$, and 128 sporadic cases. Median age of diagnosis was 50 years for the non-BRCA1/2 patients compared to 42 years $(B R C A 1)$ and 43.5 years (BRCA2) for mutation carriers and 61 years for sporadic cancer patients. Tumor and patient characteristics are summarized in Table 1 . The majority of BRCA1 tumors were
ER- (58\%) and tumor grade 3, while BRCA2 tumors were predominantly ER + (91\%) and grade 2 or 3 . Tumor grades of non-BRCA1/2 tumors were distributed more evenly, but compared to sporadic tumors, overall slightly higher. Of the non-BRCA1/2 tumors, $17 \%$ displayed triple-negative phenotype (ER-/PR-/HER2-), compared to $8 \%$ of sporadic tumors, $55 \%$ of $B R C A 1$ tumors, and 9\% of BRCA2 tumors.

\section{Subgroups within non-BRCA1/2 tumor samples are predominantly determined by ER status and molecular subtypes}

Genome wide gene expression analyses resulted in a data set consisting of 22,171 probes with unique gene symbols assigned. We performed unsupervised two-dimensional hierarchical clustering analysis of the whole series of tumors available (70 non-BRCA1/2, 33 BRCA1, 22 BRCA2 and 128 sporadic) using the 500 most variant genes (Figure 1). Two main branches were formed, separating ER-samples from ER + samples. The ER- cluster could be further subdivided into a triple-negative cluster, covering the majority of the BRCA1 tumors, a HER2+/ER-/PRcluster and a smaller mixed cluster. Tumors were classified into the intrinsic molecular subtypes (basal-like, lumA, lumB, HER2-enriched, or normal-like) by the PAM50 classifier developed by Parker et al. [20]. The triple-negative cluster consisted of only basal-like tumors, while the majority of HER2-enriched tumors were found in the HER2+/ER-/PR- cluster. Within the ER+main cluster, sub-branches enriched for $\operatorname{lum} A$ and $\operatorname{lumB}$ samples were present. 13/22 BRCA2 and 8/12 ER+ $B R C A 1$-associated tumors grouped in the lumB branches. Non-BRCA1/2 and sporadic tumors were not confined to any specific subcluster.

Clearly, hormone receptor status and molecular subtypes were the major determinants of the structure of the hierarchical clustering when including the whole series of samples. To clarify to what extent clustering of non$B R C A 1 / 2$ tumors were influenced by the presence of the $B R C A 1, B R C A 2$ and sporadic tumors, hierarchical clustering analysis was conducted using only data from non$B R C A 1 / 2$ tumor samples (Additional file 2: Figure S1). The clustering pattern of non-BRCA1/2 was found to be comparable to the initial clustering analysis, again predominantly associated with hormone receptor status and molecular subtypes.

The distribution of the PAM50 classified intrinsic molecular subtypes within non-BRCA1/2, BRCA1, BRCA2 and sporadic tumors was determined (Figure 2, Additional file 3: Figure S2, Additional file 4: Table S1). All five molecular subtypes were found within the non-BRCA1/2 tumor class. The majority of non-BRCA1/2 tumors were mainly classified as lumA $(33 / 70,47 \%)$ or lumB $(18 / 70$, 26\%), while 9 tumors were basal-like (13\%), 7 HER2- 


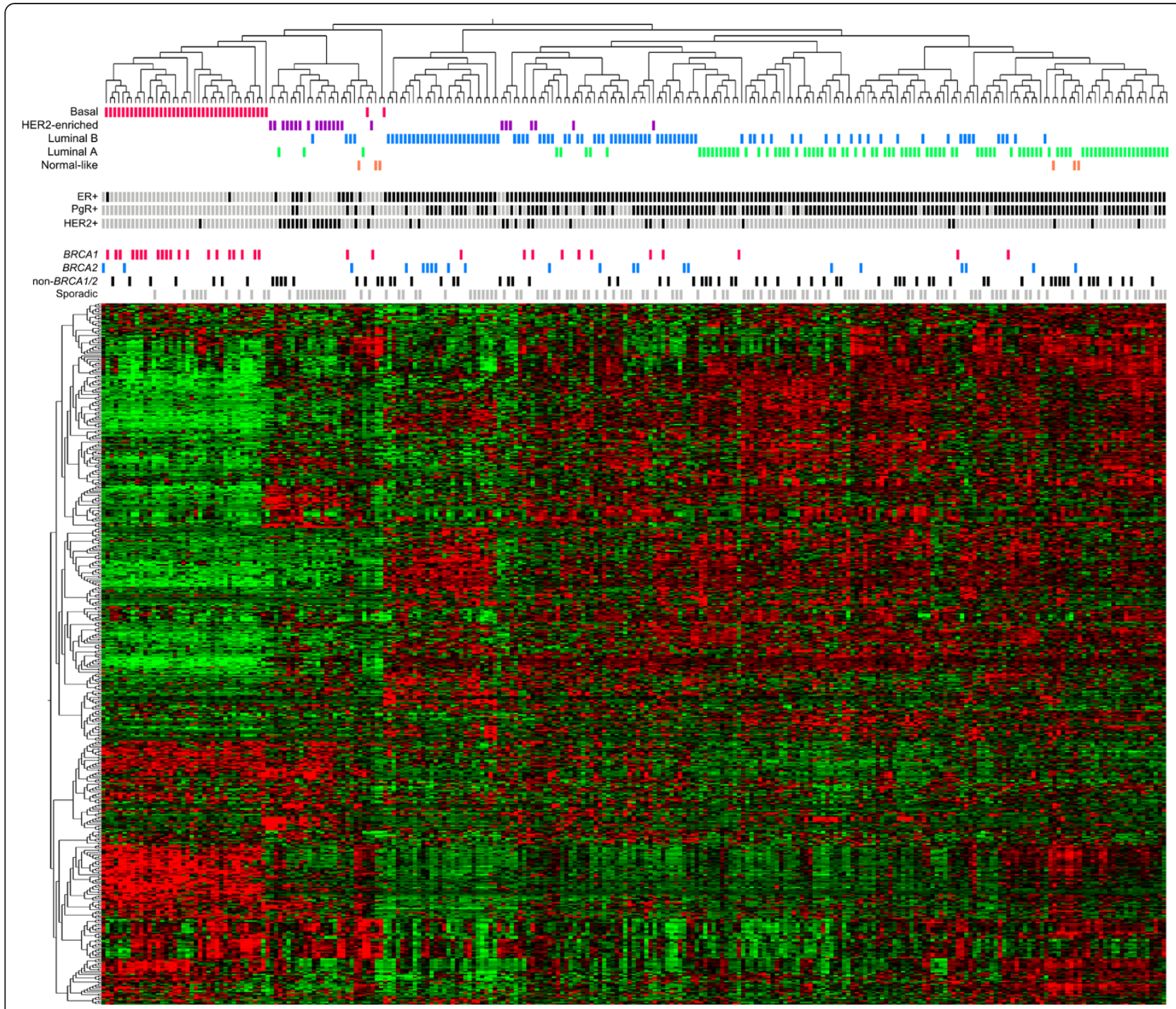

Figure 1 Hierarchical clustering of $\mathbf{2 5 3}$ breast tumor samples using the $\mathbf{5 0 0}$ most variant genes across all samples. In the heat map rows correspond to genes and columns to samples. Red indicates elevated expression, green reduced expression. Status bars designate molecular subtype, hormone receptor status and sample group.

enriched (10\%) and 3 were normal-like (4\%). The distribution of molecular subtypes among the non-BRCA1/2 tumors was similar to the distribution found in the sporadic tumors; although a tendency towards more non$B R C A 1 / 2$ tumors were basal-like while fewer were classified as lumB. On the contrary, non-BRCA1/2 tumors were markedly different from both BRCA1 and BRCA2 tumors which were highly associated with the basal-like subtype ( $\mathrm{p}=1.2 \times 10^{-6}$, Fisher's exact test) and lumB subtype $\left(\mathrm{p}=1.2 \times 10^{-4}\right.$, Fisher's exact test), respectively.

\section{BRCA-like tumors can be identified among non-BRCA1/2} tumors

We have previously developed two subtype specific gene signatures, a 110-gene basal BRCA1 signature and a 100-gene lumB $B R C A 2$ signature [24]. These signatures were here used to predict $B R C A 1$ and $B R C A 2$ association among basal-like and $\operatorname{lumB}$ non-BRCA1/2 tumors, respectively (Figure 3). Seven basal-like tumors out of nine were classified as BRCA1-like (78\%) and the remaining 2 as sporadic-like (22\%). Among the lumB subtype, 7 samples were classified as BRCA2-like (39\%) and 11 as sporadic-like (61\%). Detailed prediction results can be found in Additional file 5: Table S2.

\section{Epigenetic inactivation of BRCA1 by promoter methylation}

To identify aberrant methylation patterns in $B R C A 1$ and $B R C A 2$ promoter regions, tumor tissues were analyzed using the ME001C methylation-specific MLPA kit 


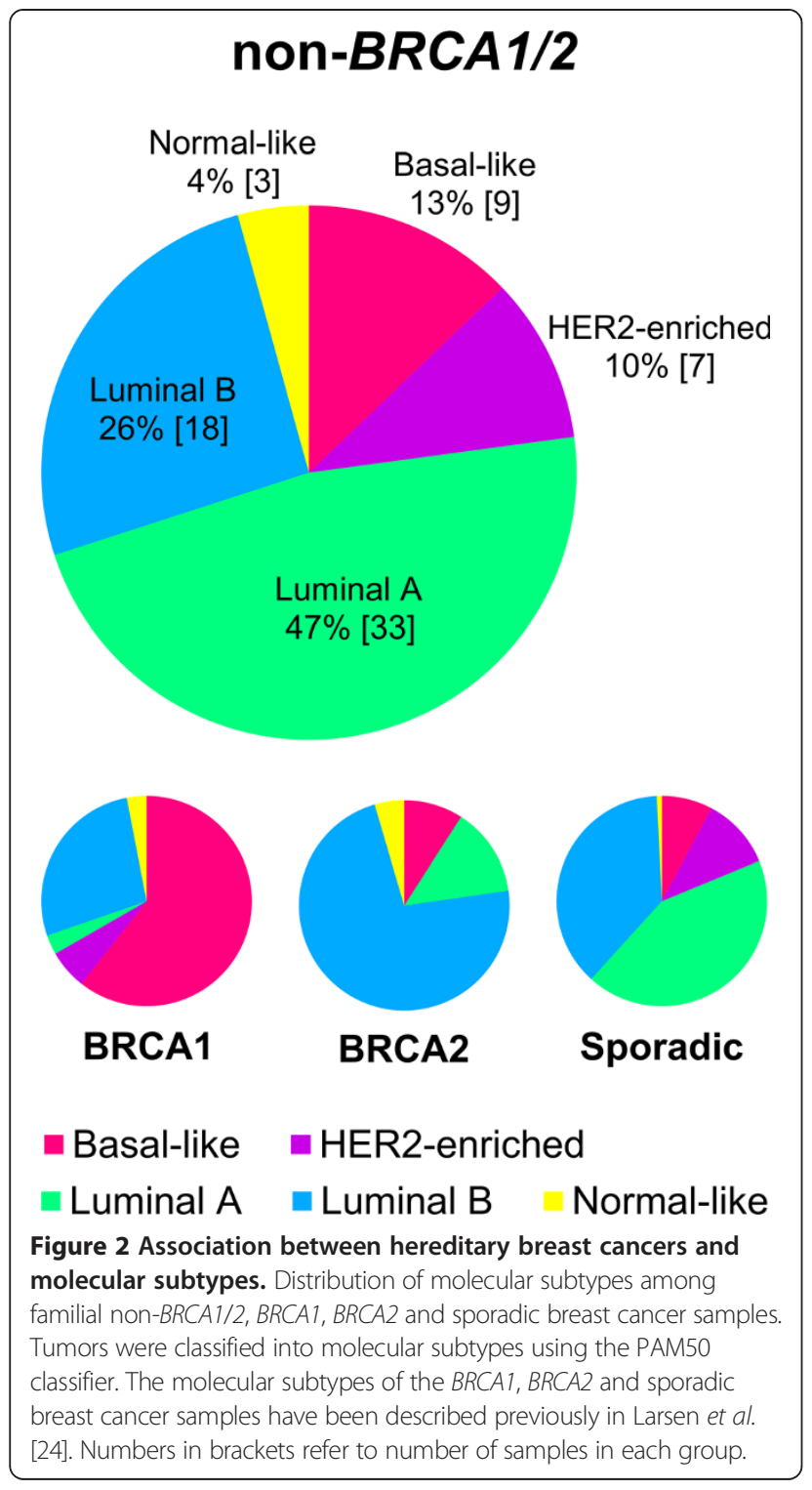

(MRC-Holland). Promoter methylation patterns were obtained from all 33 BRCA1 tumors, 18 out of 22 BRCA2 tumors, 64 out of 70 non-BRCA1/2 tumors and 120 out of 128 sporadic tumors. Six samples were found to be positive for methylation of the $B R C A 1$ promoter, counting three basal-like non-BRCA1/2 tumors, one normal-like non-BRCA1/2 tumor, one basal-like sporadic tumor and one lumB sporadic tumor. Notably, the three basal non$B R C A 1 / 2$ tumors classified as BRCA1-like were all found to have BRCA1 promoter hypermethylation. None of the cases showed methylation of the $B R C A 2$ promoter.

Methylation of the $B R C A 1$ promoter was associated with a significant reduction of the BRCA1 mRNA expression level compared to tumors not methylated in the $B R C A 1$ promoter $(p=0.024, t$-test, Additional file 6 : Figure S3). Notably, four out of the 6 methylated samples exhibited extremely low BRCA1 expression compared to the remaining non-methylated samples.

\section{Molecular subtypes aggregates within non-BRCA1/2 families}

The 70 non-BRCA1/2 patients included in the study originated from 58 breast and/or ovarian cancer families tested negative for germline mutations in BRCA1 or BRCA2. From 10 of these families, breast tumor biopsies were available from two affected family members and from a single family we obtained tumor material from three patients. The pedigrees of these eleven families are shown in Figure 4, along with corresponding molecular subtypes, $B R C A 1$ methylation status and prediction results obtained by the basal BRCA1-classifier and the lumB BRCA2-classifer. In 8 of the families we found that affected members of the same family shared the same tumor subtype. Three families were characterized by only lumA tumors, 3 families had only lumB tumors, 1 family contained only HER2-enriched tumors, and 1 family only basal-like tumors (Table 3).

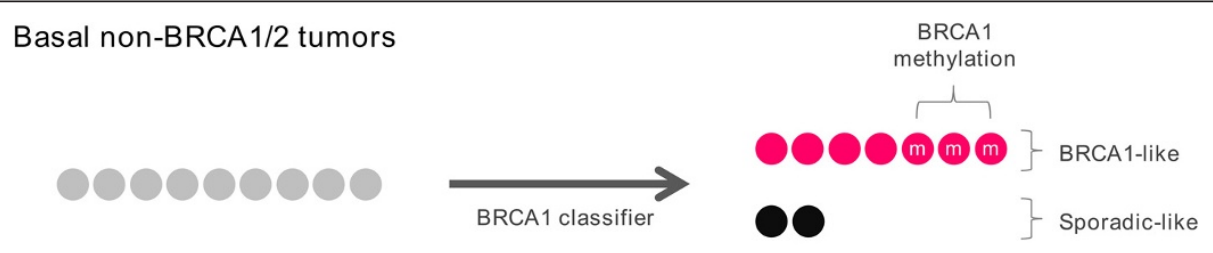

LumB non-BRCA1/2 tumors
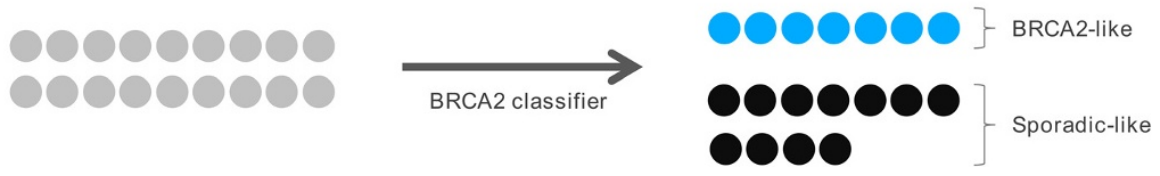

Figure 3 Prediction of $B R C A 1$ and $B R C A 2$ association among familial non-BRCA1/2 tumors. Subtype specific gene signatures were applied to predict $B R C A 1$ and $B R C A 2$ association among basal-like and lumB non-BRCA1/2 tumors, respectively. 


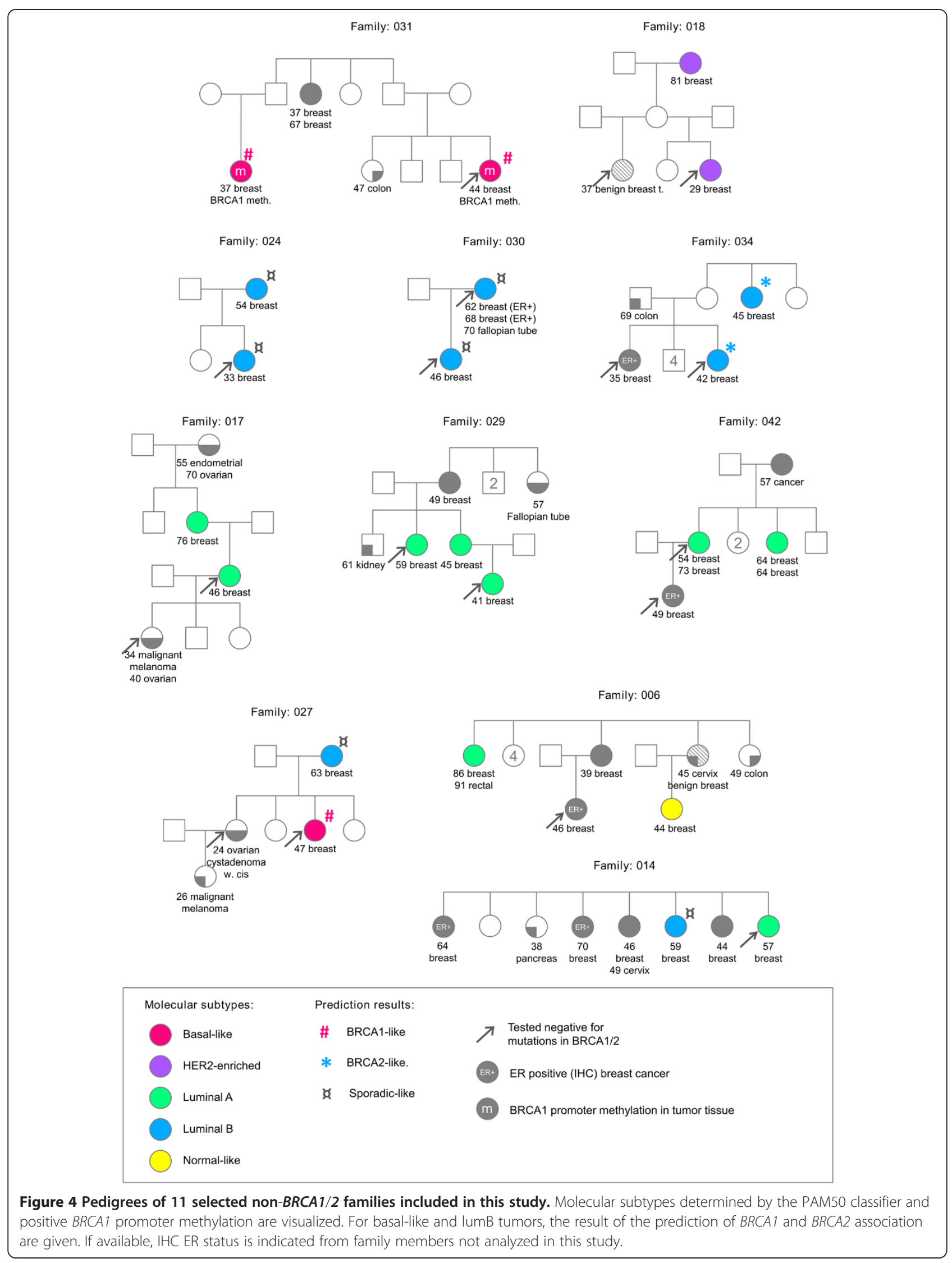


Table 3 Subtype classification of tumors from 11 families with tumor material from more than one affected individual

\begin{tabular}{lccccc}
\hline FamilyID & Basal-like & HER2-enriched & Luminal A & Luminal B & Normal-like \\
\hline $\mathbf{0 3 1}$ & 2 & - & - & - & - \\
$\mathbf{0 1 8}$ & - & 2 & - & - & - \\
$\mathbf{0 1 7}$ & - & - & 2 & - & - \\
$\mathbf{0 2 9}$ & - & - & 3 & - & - \\
$\mathbf{0 4 2}$ & - & - & - & 2 & - \\
$\mathbf{0 2 4}$ & - & - & - & 2 & - \\
$\mathbf{0 3 0}$ & - & - & - & 2 & - \\
$\mathbf{0 3 4}$ & - & - & - & 1 & - \\
$\mathbf{0 2 7}$ & 1 & - & 1 & - & 1 \\
$\mathbf{0 0 6}$ & - & - & 1 & 1 \\
$\mathbf{0 1 4}$ & - & - & -
\end{tabular}

To evaluate the significance of this finding, we performed familial aggregation testing using computer simulation as described in Materials and Methods. The result of the simulation study confirmed that the degree of familial subtypes aggregation was significant, nonrandom aggregation ( $p$-value $=1.7 \mathrm{e}-3)$.

In order to confirm the observed tendency in independent samples, we used a dataset published by Hedenfalk et al. [26]. This dataset contained gene expression profiles for tumors of 16 non-BRCA1/2 individuals, belonging to 8 different families. From five families, two or three tumors were analyzed, in total 12 samples. Subtype prediction was carried out by the PAM50 classifier (Table 4). Even though only 19 of the 50 probes were present in the Hedenfalk dataset, the same tendency was observed here. In 3 twocase families, members from the same family shared the same tumor subtypes, whereas in one family 2 normal-like tumors and one basal-like tumor were found, and another family had three different subtypes. Simulation analysis confirmed that the degree of familial aggregation was significant $(p$-value $=0.017)$.

\section{Discussion}

In this report, we investigated genome-wide RNA profiles of tumors from familial breast cancer cases where no BRCA1 or BRCA2 mutations could be identified by traditional genetic analysis for germline mutations. The search for high-susceptibility genes that can explain the breast cancer risk in the remaining non-BRCA1/2 families is complicated by their underlying genetic heterogeneity, and a probable explanation of the low success rate of attempts to identify new high-risk alleles. Obviously, intelligent stratification of cases is needed in order to reduce this heterogeneity. The aim of this study was to explore if RNA profiling can be used to identify homogeneous subgroups among these families. Subgrouping into homogeneous subsets could be of considerable value for further genetic analysis and may facilitate the identification of new high penetrance breast cancer susceptibility genes. Here we describe RNA based subgroupings among non$B R C A 1 / 2$ breast tumors, displaying strong associations with the previously described intrinsic molecular subtypes. Within these subgroups we identified tumors with $B R C A 1$ like and BRCA2-like molecular phenotype. Furthermore, we showed that breast cancer family members from the same family often show identical molecular subtypes.

\section{Molecular subtypes of familial non-BRCA1/2 tumors}

Unsupervised hierarchical clustering was used to reveal overall patterns and for identification of subgroups within the familial non-BRCA1/2 tumors. The clustering displayed a high level of heterogeneity with sub-branches mainly related to hormone receptor status and the intrinsic molecular tumor subtypes. Comparable subgroupings were observed when including a set of 33 BRCA1, 22 $B R C A 2$ and 128 sporadic tumors from our previous study [24]. Here, familial non-BRCA1/2 tumors clustered with tumors from sporadic and with $B R C A$ germline mutation

Table 4 Subtype classification of tumors from Hedenfalk et al

\begin{tabular}{lcccc}
\hline FamilyID & Basal-like & HER2-enriched & Luminal A & Normal-like \\
\hline L101 & 2 & - & - & 2 \\
L414 & - & - & - & - \\
L505 & - & - & - & - \\
L99 & 1 & 1 & 1 & - \\
L16 & 1 & & - \\
\hline
\end{tabular}


carriers, indicating that the subgroups of the familial tumors are very similar to the intrinsic molecular subtypes found among sporadic/unselected breast cancers [16,17]. Similar observations have been described by others using gene expression analysis and immunohistochemical surrogate markers for subtype classification [15,25,27-29].

In our study, familial non-BRCA1/2 tumors classified predominantly as luminal subtype with lumA tumors accounting for almost half of the tumors. The distribution of subtypes was very similar to the distribution found among sporadic tumors. Only few studies have investigated molecular subtypes with relation to familial nonBRCA1/2 tumors [22,23,25]. Jönsson et al. and Waddell et al. reported that lumA tumors were the most predominant luminal subtype among familial non-BRCA1/2 tumors, similar to what we observed in our study group, while Nagel et al. reported that lumB tumors were most frequent. These variations were however minor and might be due to differences in the inclusions criteria and subtyping methodologies used.

\section{Identification of BRCA-like tumors among familial non-BRCA1/2 tumors}

$B R C A 1$ and BRCA2 mutation screening technology traditionally include Sanger sequencing in combination with MLPA analysis. However, a fraction of mutations will still not be detected. We used a basal BRCA1 signature from our previous study to predict whether tumors with a BRCA1-like molecular phenotype were present among basal non-BRCA1/2 samples [24]. We found that $7 / 9$ (78\%) basal non-BRCA1/2 samples were BRCA1-like. In a similar approach using our lumB $B R C A 2$ signature, we identified $7 / 18$ (39\%) lumB non-BRCA1/2 tumors to be $B R C A 2$-like. This could indicate a BRCA1/2-deficiency in these tumors, either caused by an inactivating mutation not detected by current technology or epigenetic silencing such as promoter hypermethylation of the $B R C A 1 / 2$ genes or other susceptibility genes in the same pathway.

A similar approach was used to identify $B R C A 1$-like and $B R C A 2$-like tumors among non-BRCA1/2 tumors in a study by Joosse et al. using array-CGH profiles. In one study, two out of 48 non-BRCA1/2 breast tumors exhibited chromosomal aberration patterns similar to those found in BRCA1-mutated tumors, of which hypermethylation of the $B R C A 1$ promoter was demonstrated in one sample [30]. In another study focusing on $B R C A 2,12$ tumors out of 89 tumors were found to exhibit a high level of similarity with $B R C A 2$-mutated breast tumors [31]. In two cases, additional indications of a dysfunctional $B R C A 2$ gene function were observed.

\section{Promoter methylation}

To find further evidence for $B R C A 1$ or $B R C A 2$ involvement in the familial non- $B R C A 1 / 2$ tumors, we performed methylation-specific MLPA analysis of the BRCA1 and $B R C A 2$ promoter regions. Four non-BRCA1/2 samples were found to be methylated in the $B R C A 1$ promoter region (3 basal-like, 1 normal-like). Notably, the three basal-like tumors were all found also to have a BRCA1like expression profile. This supports the hypothesis that tumors with epigenetic silencing of $B R C A 1$ by promoter hyper-methylation are similar to $B R C A 1$ mutated tumors [30,32-34]. The absence of $B R C A 2$ promoter methylation in our sample group is in line with previous observations [35].

\section{Aggregation of molecular subtypes within non-BRCA1/2 families}

It is well established that families carrying a germline $B R C A 1$ mutation have increased incidence of basal-like/ triple-negative breast cancers, while germline $B R C A 2$ mutations predispose to cancers of the lumB subtype [22-24]. If the same tendency is true for defects in other high penetrance breast cancer genes, tumors from genetically related patients would exhibit related molecular subtypes, as it is the case for BRCA1 and BRCA2 families. The 70 familial non-BRCA1/2 cases included in the current study, originated from 58 breast cancer families with tumor material from one affected family member and from 11 families with tumor material from more than one affected individual. This gave us a unique opportunity to investigate the "same gene - same subtype" hypothesis. Convincingly, we found that members of the same family shared the same tumor subtype in 8 of the 11 families. Three of the families were characterized by lumA tumors only (including the 3-case family), three families had lumB tumors, one had HER2-enriched tumors and one had only basal-like tumors. By computer simulation we found that the observed familial aggregation was highly unlikely to be a chance observation.

In order to confirm our observations, we identified a dataset from a study by Hedenfalk et al. where gene expression data were available from tumors from 5 high-risk families negative for BRCA1/2 mutations [26]. Three 2-case families showed full concordance, while a 3-case family contained 2 normal-like samples and 1 basal-like, and another 3-case family was represented by 3 different subtypes. Again, computer simulation confirmed this as significantly different from random.

Our observations indicate an underlying common genetic basis in these families and that the cancers in the families are unlikely to be sporadic of origin. The family members may carry an inherited susceptibility not just to breast cancer but to a particular subtype of breast cancer. In support of the "same gene - same subtype" hypothesis, in a study by Waddell et al. the authors noticed that all tumor biopsies from ATM mutation carriers included in their study were classified as luminal 
(4 $\operatorname{lumB}$ and $2 \operatorname{lum} \mathrm{A})$ [36]. Within a large non-BRCA1/2 family, four out of five family members were classified as lumA. Furthermore, a study by Nagel et al. included a group of 26 breast tumors from CHEK2 1100delC carriers; all were classified as luminal tumors (8 LumA and 18 LumB). On the contrary, a study analyzing tumors using IHC noted that different tumors within the same family frequently belonged to different phenotype categories [37]. This discrepancy may, however, be related to differences in methodology and/or inclusion criteria. In addition, in a recent study by Didraga et al., a specific tumor arrayCGH profile has been shown to cluster within a subgroup of non-BRCA1/2 families [38].

Segregation studies have indicated that the remaining genetic susceptibility within non-BRCA1/2 families may be explained by a mixture of rare high-risk variants and polygenic mechanisms involving more common and/or rare low-penetrance alleles or rare moderate penetrance genes, acting in concert to confer a high breast cancer risk. Our observations that family members often shares the same molecular subtype may be compatible with both scenarios. The cancer-risk and tumor subtype may be a result of either private mutations in high-penetrance genes or be a result of multiple low/moderate penetrant genes acting in concert.

In our study, BRCA1 promoter methylation was detected in breast tumors from both women in a family with basal-like tumors (Family 031). Involvement of BRCA1 was further supported as both tumors were predicted to be BRCA1-like by expression analysis. To investigate if $B R C A 1$ methylation could be due to an inherited trait in this family we analyzed DNA from peripheral blood leukocytes available from one of the women. No aberrant BRCA1 methylation pattern in the blood sample was detected by the MLPA method.

In the 3 pure lumB families, we found full concordance in the BRCA2-like prediction results between family members of the same family. Tumors from one lumB family were classified as $B R C A 2$-like, which could indicate inactivation of $B R C A 2$ or related genes. In two other lumB families all members were classified as non$B R C A 2$-like (sporadic-like), indicating that $B R C A 2$ is less likely to be involved in the development of cancer in these families.

\section{Conclusions}

Familial non-BRCA1/2 breast tumors comprising a molecularly heterogeneous group of cancers can be further classified by RNA profiling into subgroups showing high resemblance to the intrinsic molecular subtypes. To the best of our knowledge this is the first study to systematically demonstrate that members of the same family often share the same molecular breast cancer subtype, indicating that germline inactivation of certain genes may give rise to specific breast cancer subtypes. These findings could be highly relevant when analyzing data from next generation sequencing of affected family members. Although additional validation studies are required to confirm this tendency, our findings suggest that future genetic analysis may benefit from stratifying tumors/families into molecularly homogeneous subtypes in order to identify new high penetrance susceptibility genes.

\section{Additional files}

\begin{abstract}
Additional file 1: Methods S1. Preparation of validation dataset.
Additional file 2: Figure S1. Unsupervised hierarchical clustering of
\end{abstract} non-BRCA1/2 tumor samples using the 200 most variant genes.

Additional file 3: Figure S2. PCA plots visualizing molecular subtype classifications.

Additional file 4: Table S1. Distribution of predicted molecular subtypes within BRCA1, BRCA2, non-BRCA1/2 and sporadic tumors using PAM50 signature.

Additional file 5: Table S2. Patients characteristics and BRCA1-like and $B R C A 2$-like predictions results for familial non-BRCA1/2 patients.

Additional file 6: Figure S3. Relations between $B R C A 1$ gene expression and BRCA1 promoter methylation and PAM50 molecular subtypes.

\section{Competing interests}

The authors have declared that no competing interests exist.

\section{Authors' contributions}

$M J L, A M G, M T$, and TAK conceived the study and designed the experiments; $A V L, M B, M K A$ and $A M G$ were involved in acquisition of materials and data; MJL and KPS carried out the experiments; MJL performed the data analysis; $M J L, A M G, M T, Q T$, and TAK were involved in the interpretation of the results; MJL, with the support of all authors, wrote the paper. All authors were involved in revising the paper and had final approval of the submitted version.

\section{Acknowledgments}

The authors acknowledge Ingrid Hedenfalk and colleagues for making their microarray dataset publically available. The work was supported by a gift from Heidi Seide Jacobsen and grants from Ministry of the Interior and Ministry of Health, University of Southern Denmark, Odense University Hospital, Danish Cancer Society, The Danish Council for Strategic Research (DBCG-TIBCAT), Dansk Kræftforsknings Fond, Breast Friends, Københavns Universitets fond for kræftforskning, Savværksejer Jeppe Juhls og hustru Ovita Juhls Mindelegat, Arvid Nilssons Fond, Agnes og Poul Friis Fond, Raimond og Dagmar Ringgård Bohns Fond, Fonden til Lægevidenskabens Fremme, Kong Christian IX og Dronning Louises Jubilæumslegat, Ingeniør K. A. Rohde og hustrus Legat, Snedkermester Sophus Jacobsens og hustru Astrid Jacobsens Fond, Fru Astrid Thaysens Legat for Lægevidenskabelig Grundforskning, Helen Rudes Fond, Karen A. Tolstrups Fond, A.J. Andersen og Hustrus Fond, Dagmar Marshalls Fond, Aase og Ejnar Danielsens Fond, Grosserer M. Brogaard og Hustrus Mindefonde, Augustinus Fonden, Familien Hede Nielsens Fond.

\section{Author details}

'Department of Clinical Genetics, Odense University Hospital, Sdr. Boulevard 29, Odense 5000, Denmark. ${ }^{2}$ Human Genetics, Clinical Institute, University of Southern Denmark, Odense, Denmark. ${ }^{3}$ Epidemiology, Biostatistics and Biodemography, Institute of Public Health, University of Southern Denmark, Odense, Denmark. ${ }^{4}$ Slagelse Hospital, Department of Pathology, Slagelse, Denmark. 5 Department of Pathology, Odense University Hospital, Odense, Denmark. ${ }^{6}$ Department of Clinical Genetics, Rigshospitalet, Copenhagen University Hospital, Copenhagen, Denmark. 
Received: 23 October 2013 Accepted: 24 January 2014

Published: 31 January 2014

\section{References}

1. Jemal A, Bray F, Center MM, Ferlay J, Ward E, Forman D: Global cancer statistics. CA Cancer J Clin 2011, 61:69-90.

2. Gerdes A-M, Cruger DG, Thomassen M, Kruse TA: Evaluation of two different models to predict BRCA1 and BRCA2 mutations in a cohort of Danish hereditary breast and/or ovarian cancer families. Clin Genet 2006, 69:171-178.

3. Melchor L, Benítez J: The complex genetic landscape of familial breast cancer. Hum Genet 2013, 132:845-863.

4. Smith P, McGuffog L, Easton DF, Mann GJ, Pupo GM, Newman B, ChenevixTrench G, Szabo C, Southey M, Renard H, Odefrey F, Lynch H, Stoppa-Lyonnet D, Couch F, Hopper JL, Giles GG, McCredie MRE, Buys S, Andrulis I, Senie R, Goldgar DE, Oldenburg R, Kroeze-Jansema K, Kraan J, Meijers-Heijboer H, Klijn JGM, Van Asperen C, Van Leeuwen I, Vasen HFA, Cornelisse CJ: A genome wide linkage search for breast cancer susceptibility genes. Genes Chromosom Cancer 2006, 45:646-655.

5. Rosa-Rosa JM, Pita G, Urioste M, Llort G, Brunet J, Lázaro C, Blanco I, Ramón Y, Cajal T, Díez O, De La Hoya M, Caldés T, Tejada M-I, González-Neira A, Benítez J: Genome-wide Linkage scan reveals three putative breast-cancersusceptibility Loci. Am J Hum Genet 2009, 84:115-122.

6. Arason A, Gunnarsson H, Johannesdottir G, Jonasson K, Bendahl P-O, Gillanders E, Agnarsson B, Jonsson G, Pylkas K, Mustonen A, Heikkinen T, Aittomaki K, Blomqvist C, Melin B, Johannsson O, Moller P, Winqvist R, Nevanlinna $H_{\text {, }}$ Borg A, Barkardottir R: Genome-wide search for breast cancer linkage in large Icelandic non-BRCA1/2 families. Breast Cancer Res 2010, 12:R50.

7. Snape K, Ruark E, Tarpey P, Renwick A, Turnbull C, Seal S, Murray A, Hanks S, Douglas J, Stratton M, Rahman N: Predisposition gene identification in common cancers by exome sequencing: insights from familial breast cancer. Breast Cancer Res Treat 2012, 134(1):429-433.

8. Gracia-Aznarez FJ, Fernandez V, Pita G, Peterlongo P, Dominguez O, de la Hoya M, Duran M, Osorio A, Moreno L, Gonzalez-Neira A, Rosa-Rosa JM, Sinilnikova O, Mazoyer S, Hopper J, Lazaro C, Southey M, Odefrey F, Manoukian S, Catucci I, Caldes T, Lynch HT, Hilbers FSM, Van Asperen CJ, Vasen HFA, Goldgar D, Radice $P$, Devilee $P$, Benitez $\mathrm{J}$ : Whole exome sequencing suggests much of non-BRCA1/BRCA2 familial breast cancer is due to moderate and low penetrance susceptibility alleles. PLOS ONE 2013, 8:e55681.

9. Hilbers FS, Meijers CM, Laros JFJ, Van Galen M, Hoogerbrugge N, Vasen HFA, Nederlof PM, Wijnen JT, Van Asperen CJ, Devilee P: Exome sequencing of Germline DNA from Non-BRCA1/2 familial breast cancer cases selected on the basis of aCGH tumor profiling. PLOS ONE 2013, 8:e55734.

10. Turnbull C, Rahman N: Genetic predisposition to breast cancer: past, present, and future. Annu Rev Genomics Hum Genet 2008, 9:321-345.

11. Eccles SA, Aboagye EO, Ali S, Anderson AS, Armes J, Berditchevski F, Blaydes JP, Brennan K, Brown NJ, Bryant HE, Bundred NJ, Burchell JM, Campbell AM, Carroll JS, Clarke RB, Coles CE, Cook GJ, Cox A, Curtin NJ, Dekker LV, Silva I, Dos S, Duffy SW, Easton DF, Eccles DM, Edwards DR, Edwards J, Evans DG, Fenlon DF, Flanagan JM, Foster C: Critical research gaps and translational priorities for the successful prevention and treatment of breast cancer. Breast Cancer Res 2013, 15:R92.

12. Vargas AC, Reis-Filho JS, Lakhani SR: Phenotype-genotype correlation in familial breast cancer. J Mammary Gland Biol Neoplasia 2011, 16:27-40.

13. Mavaddat N, Barrowdale D, Andrulis IL, Domchek SM, Eccles D, Nevanlinna H, Ramus SJ, Spurdle A, Robson M, Sherman M, Mulligan AM, Couch FJ, Engel C, McGuffog L, Healey S, Sinilnikova OM, Southey MC, Terry MB, Goldgar D, O'Malley F, John EM, Janavicius R, Tihomirova L, Hansen TVO, Nielsen FC, Osorio A, Stavropoulou A, Benítez J, Manoukian S, Peissel B, et al: Pathology of breast and ovarian cancers among BRCA1 and BRCA2 mutation carriers: results from the consortium of investigators of modifiers of BRCA1/2 (CIMBA). Cancer Epidemiology Biomarkers \& Prevention 2012, 21:134-147.

14. Lakhani SR, Gusterson BA, Jacquemier J, Sloane JP, Anderson TJ, Van De Vijver MJ, Venter D, Freeman A, Antoniou A, McGuffog L, Smyth E, Steel CM, Haites N, Scott RJ, Goldgar D, Neuhausen S, Daly PA, Ormiston W, McManus R, Scherneck S, Ponder BAJ, Futreal PA, Peto J, Stoppa-Lyonnet D, Bignon Y-J, Struewing JP, Bishop DT, Klijn JGM, Devilee P, Cornelisse CJ, et al: The pathology of familial breast cancer: histological features of cancers in families not attributable to mutations in BRCA1 or BRCA2. Clin Cancer Res 2000, 6:782-789.

15. Honrado E, Osorio A, Milne RL, Paz MF, Melchor L, Cascón A, Urioste M, Cazorla A, Díez O, Lerma E, Esteller M, Palacios J, Benitez J:
Immunohistochemical classification of non-BRCA1/2 tumors identifies different groups that demonstrate the heterogeneity of BRCAX families. Mod Pathol 2007, 20:1298-1306.

16. Sørlie T, Tibshirani R, Parker J, Hastie T, Marron JS, Nobel A, Deng S, Johnsen H, Pesich R, Geisler S, Demeter J, Perou CM, Lønning PE, Brown PO, Børresen-Dale A-L, Botstein D: Repeated observation of breast tumor subtypes in independent gene expression data sets. Proc Natl Acad Sci USA 2003, 100:8418-8423.

17. Hu Z, Fan C, Oh DS, Marron JS, He X, Qaqish BF, Livasy C, Carey LA, Reynolds E, Dressler L, Nobel A, Parker J, Ewend MG, Sawyer LR, Wu J, Liu Y, Nanda R, Tretiakova M, Orrico AR, Dreher D, Palazzo JP, Perreard L, Nelson E, Mone M, Hansen H, Mullins M, Quackenbush JF, Ellis MJ, Olopade OI, Bernard PS, et al: The molecular portraits of breast tumors are conserved across microarray platforms. BMC Genomics 2006, 7:96.

18. Yu K, Lee $\mathrm{CH}$, Tan PH, Tan P: Conservation of breast cancer molecular subtypes and transcriptional patterns of tumor progression across distinct ethnic populations. Clin Cancer Res 2004, 10:5508-5517.

19. Sørlie T, Perou CM, Tibshirani R, Aas T, Geisler S, Johnsen H, Hastie T, Eisen MB, van de Rijn M, Jeffrey SS, Thorsen T, Quist H, Matese JC, Brown PO, Botstein D, Lønning PE, Børresen-Dale A-L: Gene expression patterns of breast carcinomas distinguish tumor subclasses with clinical implications. Proc Natl Acad Sci USA 2001, 98:10869-10874.

20. Parker JS, Mullins M, Cheang MCU, Leung S, Voduc D, Vickery T, Davies S, Fauron C, He X, Hu Z, Quackenbush JF, Stijleman IJ, Palazzo J, Marron JS, Nobel AB, Mardis E, Nielsen TO, Ellis MJ, Perou CM, Bernard PS: Supervised risk predictor of breast cancer based on intrinsic subtypes. J Clin Oncol 2009, 27:1160-1167.

21. Perou CM, Sorlie T, Eisen MB, van de Rijn M, Jeffrey SS, Rees CA, Pollack JR, Ross DT, Johnsen H, Akslen LA, Fluge O, Pergamenschikov A, Williams C, Zhu SX, Lonning PE, Borresen-Dale A-L, Brown PO, Botstein D: Molecular portraits of human breast tumours. Nature 2000, 406:747-752.

22. Waddell N, Arnold J, Cocciardi S, Da Silva L, Marsh A, Riley J, Johnstone CN, Orloff M, Assie G, Eng C, Reid L, Keith P, Yan M, Fox S, Devilee P, Godwin AK, Hogenorst FBL, Couch F, Grimmond S, Flanagan JM, Khanna K, Simpson PT, Lakhani SR, Chenevix-Trench G: Subtypes of familial breast tumours revealed by expression and copy number profiling. Breast Cancer Res Treat 2010, 123:661-677.

23. Jönsson G, Staaf J, Vallon-Christersson J, Ringnér M, Holm K, Hegardt C, Gunnarsson H, Fagerholm R, Strand C, Agnarsson BA, Kilpivaara O, Luts L, Heikkilä P, Aittomäki K, Blomqvist C, Loman N, Malmström P, Olsson H, Th Johannsson O, Arason A, Nevanlinna H, Barkardottir RB, Borg A: Genomic subtypes of breast cancer identified by array-comparative genomic hybridization display distinct molecular and clinical characteristics. Breast Cancer Res 2010, 12:R42.

24. Larsen MJ, Kruse TA, Tan Q, Lænkholm A-V, Bak M, Lykkesfeldt AE, Sørensen KP, Hansen TVO, Ejlertsen B, Gerdes A-M, Thomassen M: Classifications within molecular subtypes enables identification of BRCA1/BRCA2 mutation carriers by RNA tumor profiling. PLOS ONE 2013, 8:e64268.

25. Nagel JHA, Peeters JK, Smid M, Sieuwerts AM, Wasielewski M, De Weerd V, Trapman-Jansen AMAC, Van Den Ouweland A, Brüggenwirth H, Jcken WFJ VI, Klijn JGM, Van Der Spek PJ, Foekens JA, Martens JWM, Schutte M, Meijers-Heijboer $\mathrm{H}$ : Gene expression profiling assigns CHEK2 1100delC breast cancers to the luminal intrinsic subtypes. Breast Cancer Res Treat 2012, 132:439-448.

26. Hedenfalk I, Ringnér M, Ben-Dor A, Yakhini Z, Chen Y, Chebil G, Ach R, Loman N, Olsson H, Meltzer P, Borg A, Trent J: Molecular classification of familial non-BRCA1/BRCA2 breast cancer. Proc Natl Acad Sci USA 2003, 100:2532-2537.

27. Fernández-Ramires R, Gómez G, Muñoz-Repeto I, De Cecco L, Llort G, Cazorla A, Blanco I, Gariboldi M, Pierotti MA, Benítez J, Osorio A: Transcriptional characteristics of familial non-BRCA1/BRCA2 breast tumors. Int J Cancer 2011, 128:2635-2644.

28. Melchor L, Honrado E, García MJ, Alvarez S, Palacios J, Osorio A, Nathanson KL, Benítez J: Distinct genomic aberration patterns are found in familial breast cancer associated with different immunohistochemical subtypes. Oncogene 2008, 27:3165-3175.

29. Jönsson G, Staaf J, Vallon-Christersson J, Ringnér M, Gruvberger-Saal SK, Saal LH, Holm K, Hegardt C, Arason A, Fagerholm R, Persson C, Grabau D, Johnsson E, Lövgren K, Magnusson L, Heikkilä P, Agnarsson BA, Johannsson OT, Malmström P, Fernö M, Olsson H, Loman N, Nevanlinna 
$H$, Barkardottir RB, Borg A: The retinoblastoma gene undergoes rearrangements in BRCA1-deficient basal-like breast cancer. Cancer Res 2012, 72:4028-4036.

30. Joosse SA, Brandwijk KIM, Mulder L, Wesseling J, Hannemann J, Nederlof PM: Genomic signature of BRCA1 deficiency in sporadic basal-like breast tumors. Genes Chromosom Cancer 2011, 50:71-81.

31. Joosse SA, Brandwijk KIM, Devilee P, Wesseling J, Hogervorst FBL, Verhoef S, Nederlof PM: Prediction of BRCA2-association in hereditary breast carcinomas using array-CGH. Breast Cancer Res Treat 2012, 132:379-389.

32. Hedenfalk I, Duggan D, Chen Y, Radmacher M, Bittner M, Simon R, Meltzer P, Gusterson B, Esteller M, Raffeld M, Yakhini Z, Ben-Dor A, Dougherty E, Kononen J, Bubendorf L, Fehrle W, Pittaluga S, Gruvberger S, Loman N, Johannsson O, Olsson H, Wilfond B, Sauter G, Kallioniemi O-P, Borg A, Trent J: Gene-expression profiles in hereditary breast cancer. N Engl J Med 2001, 344:539-548.

33. Veer $L$ V 't, Dai H, Van De Vijver MJ, He YD, Hart AAM, Mao M, Peterse HL, Van Der Kooy K, Marton MJ, Witteveen AT, Schreiber GJ, Kerkhoven RM, Roberts C, Linsley PS, Bernards R, Friend SH: Gene expression profiling predicts clinical outcome of breast cancer. Nature 2002, 415:530-536.

34. Alvarez S, Diaz-Uriarte R, Osorio A, Barroso A, Melchor L, Paz MF, Honrado E, Rodríguez R, Urioste M, Valle L, Díez O, Cigudosa JC, Dopazo J, Esteller M, Benitez J: A predictor based on the somatic genomic changes of the BRCA1/BRCA2 breast cancer tumors identifies the non-BRCA1/BRCA2 tumors with BRCA1 promoter hypermethylation. Clin Cancer Res 2005, 11:1146-1153.

35. Collins N, Wooster R, Stratton MR: Absence of methylation of CpG dinucleotides within the promoter of the breast cancer susceptibility gene BRCA2 in normal tissues and in breast and ovarian cancers. Br J Cancer 1997, 76:1150-1156.

36. Waddell N, Cocciardi S, Johnson J, Healey S, Marsh A, Riley J, Da Silva L, Vargas AC, Reid L, Simpson PT, Lakhani SR, Chenevix-Trench G: Gene expression profiling of formalin-fixed, paraffin-embedded familial breast tumours using the whole genome-DASL assay. J Pathol 2010, 221:452-461.

37. Oldenburg RA, Kroeze-Jansema K, Meijers-Heijboer H, Van Asperen CJ, Hoogerbrugge N, Van Leeuwen I, Vasen HFA, Cleton-Jansen A-M, Kraan J, Houwing-Duistermaat JJ, Morreau H, Cornelisse CJ, Devilee P. Characterization of familial non-BRCA1/2 breast tumors by loss of heterozygosity and immunophenotyping. Clin Cancer Res 2006, 12:1693-1700

38. Didraga MA, Van Beers EH, Joosse SA, Brandwijk KIM, Oldenburg RA, Wessels LFA, Hogervorst FBL, Ligtenberg MJ, Hoogerbrugge N, Verhoef S, Devilee P, Nederlof PM: A non-BRCA1/2 hereditary breast cancer subgroup defined by aCGH profiling of genetically related patients. Breast Cancer Res Treat 2011, 130:425-436.

doi:10.1186/1755-8794-7-9

Cite this article as: Larsen et al: RNA profiling reveals familial aggregation of molecular subtypes in non-BRCA1/2 breast cancer families. BMC Medical Genomics 2014 7:9.

\section{Submit your next manuscript to BioMed Central and take full advantage of:}

- Convenient online submission

- Thorough peer review

- No space constraints or color figure charges

- Immediate publication on acceptance

- Inclusion in PubMed, CAS, Scopus and Google Scholar

- Research which is freely available for redistribution 